\title{
Correction to: Usefulness of MOG-antibody titres at first episode to predict the future clinical course in adults
}

\author{
Alvaro Cobo-Calvo ${ }^{1,2} \cdot$ María Sepúlveda $^{3} \cdot$ Hyacintha d'Indy ${ }^{2}$ Thais Armanguée ${ }^{3,4} \cdot$ Anne Ruiz $^{2}$ - Elisabeth Maillart ${ }^{5}$. \\ Caroline Papeix ${ }^{5} \cdot$ Bertrand Audoin $^{6} \cdot$ Helene Zephir $^{7} \cdot$ Damien Biotti $^{8} \cdot$ Jonathan Ciron $^{8} \cdot$ Francoise Durand-Dubief $^{1}$. \\ Nicolas Collongues ${ }^{9} \cdot$ Xavier Ayrignac $^{10} \cdot$ Pierre Labauge $^{10} \cdot$ Eric Thouvenot $^{11} \cdot$ Alexis Montcuquet $^{12}$. \\ Romain Deschamps ${ }^{13} \cdot$ Nuria Solà-Valls $^{3}$ - Sara Llufriu ${ }^{3} \cdot$ Yolanda Blanco $^{3}$. Jerome de Seze ${ }^{9}$. Sandra Vukusic ${ }^{1,14,15}$. \\ Albert Saiz $^{3} \cdot$ Romain Marignier ${ }^{1,2,15}$ on behalf of The OFSEP Group $\cdot$ The REEM Group
}

Published online: 7 February 2019

(c) Springer-Verlag GmbH Germany, part of Springer Nature 2019

\section{Correction to: Journal of Neurology} https://doi.org/10.1007/s00415-018-9160-9

The original version of this article unfortunately contained a mistake. There is a mistake in the surname of the third author of the manuscript. She is Hyacintha d'Indy and not Hyacintha 'Indy.

The original article has been corrected.

The original article can be found online at https://doi.org/10.1007/ s00415-018-9160-9.

Alvaro Cobo-Calvo

alvaro.cobo-calvo@chu-lyon.fr

1 Service de neurologie, sclérose en plaques, pathologies de la myéline et neuro-inflammation and Centre de référence pour les maladies inflammatoires rares du cerveau et de la moelle (MIRCEM), Hôpital Neurologique Pierre Wertheimer Hospices Civils de Lyon, 59 boulevard Pinel, BRON cedex, 69677 Lyon, France

2 Lyon's Neuroscience Research Center, U1028 INSERM, UMR5292 CNRS, FLUID Team, 69008 Lyon, France

3 Institut d'Investigació Biomèdica August Pi i Sunyer (IDIBAPS), Center of Neuroimmunology, Neurology Department, Hospital Clínic, Barcelona, Spain

4 Pediatric Neuroimmunology Unit, Department of Neurology, Sant Joan de Deu Children's Hospital, University of Barcelona, Barcelona, Spain

5 Department of Neurology, Pitié-Salpêtrière Hospital, APHP, Paris, France

6 Pôle de Neurosciences Cliniques, Service de Neurologie, Aix Marseille Univ, APHM, Hôpital de La Timone, Marseille, France
7 Pôle des Neurosciences et de l'Appareil Locomoteur, CHU de Lille, Université de Lille, LIRIC, UMR 995, Lille, France

8 Department of Neurology B4, Bâtiment Pierre-Paul Riquet, University Hospital of Purpan, Toulouse, France

9 Department of Neurology and Clinical Investigation Center, Strasbourg University Hospital, Strasbourg, France

10 Multiple Sclerosis Unit, Montpellier University Hospital, Montpellier, France

11 Department of Neurology, Hôpital Carémeau, Nimes University Hospital, Nimes, France

12 Department of Neurology, Hôpital de Dupuytren, Limoges, France

13 Department of Neurology, Fondation A. De Rothschild, Paris, France

14 Lyon's Neuroscience Research Center, Observatoire Français de la Sclérose en Plaques, INSERM 1028 et CNRS UMR5292, 69003 Lyon, France

15 Université Claude Bernard Lyon 1, Université de Lyon, 69100 Lyon, France 